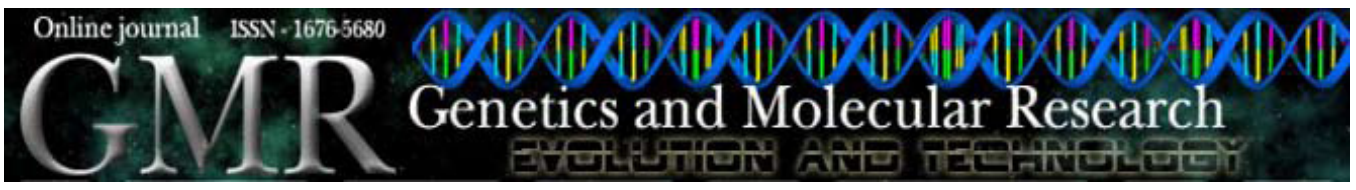

\title{
Variation in genotypic responses and biochemical analysis of callus induction in cultivated wheat
}

\author{
M.M. Shah', Q. Khalid', U.W. Khan', S.A.H. Shah ${ }^{3}$, S.H. Shah², \\ A. Hassan ${ }^{1}$ and A. Pervez ${ }^{1}$ \\ ${ }^{1}$ Department of Environmental Sciences, \\ COMSATS (Commission on Science and Technology for Sustainable \\ Development in the South) Institute of Information Technology, \\ Abbottabad, Pakistan \\ ${ }^{2}$ Institute of Biotechnology and Genetic Engineering, NWFP, \\ Agricultural University, Peshawar, Pakistan \\ ${ }^{3}$ Department of Horticulture, NWFP, Agricultural University, \\ Peshawar, Pakistan \\ Corresponding author: M.M. Shah \\ E-mail:mmshah@ciit.net.pk
}

Genet. Mol. Res. 8 (3): 783-793 (2009)

Received August 28, 2008

Accepted May 10, 2009

Published July 14, 2009

\begin{abstract}
Wheat is notorious for callus induction, which is a major hindrance in direct gene transfer and consequently for genetic improvement programs. In order to provide a successful platform for gene transformation, good callus quantity and quality is important. We investigated the variation in callus induction capabilities of Pakistani wheat cultivars and measured the reducing sugar content in the induced calluses. Ten elite wheat varieties, developed and cultivated in Pakistan were selected on the basis of agronomic and stress tolerance parameters. Significant differences were found
\end{abstract}


between and among wheat cultivars for callus induction response, shoot length and callus quality. The callus induction responses of Punjab-81, Punjab-96 and Zarghoon-79 were found to be the best among the 10 varieties. The induced calluses were of two types, embryogenic (hard) and non-embryogenic (soft). The seeds gave good germination. The highest reducing sugar concentration was found in cultivar Sutlaj-86, which needs to be tested for stress resistance, a measure of its utility for genetic engineering programs. The relative callus induction rate and reducing sugar content of the wheat cultivars were found to be genotype-dependent.

Key words: Callus; Embryogenic; Genotypic response; Tissue culture; Triticum aestivum; Wheat

\section{INTRODUCTION}

Bread wheat (Triticum aestivum L.) is an allohexaploid, containing three distinct but genetically related (homologous) copies of chromosomes each from the three originally independent haploid genomes, the A, B, and D (Gill and Gill, 1994). The triplicate nature of genome coupled with its large size $(\sim 1.6 \mathrm{MB})$ make it difficult to improve wheat crop using conventional genetic tools. One of the most modern and efficient techniques is the direct gene transfer across genera and species. However, most of the genetic engineering techniques require good quality callus production with an optimum quantity for transformation and regeneration.

The potential value of cell, tissue and anther culture as a tool for crop improvement has been reported over several decades (Green, 1977; Vasil, 1987). The regeneration of whole plant is possible today from cereal species, such as bread wheat (Redway et al., 1990; Vasil et al., 1990), maize (Duncan et al., 1985), rice (Yamada et al., 1986), and barley (Lührs and Lörz, 1988). La Rue (1949) raised the first successful tissue culture in cereals from endosperm. In vitro regeneration of wheat is possible from different explants such as mature and immature embryos, seeds, endosperm, leaves, shoot bases, and root tips (Sarker and Biswas, 2002). Immature embryo was reported as the best tissue for callus induction and shoot regeneration (Arzani and Mirodjagh, 1999; Sarker and Biswas, 2002); but availability of immature embryo is limited by wheat growing season or requires sophisticated growth chambers. On the other hand, mature seeds of wheat are readily available throughout the year, hence can be used for plant regeneration at any time. High frequency of callus induction is also reported through mature embryo culture in wheat (Ozagen et al., 1998). Establishing an efficient tissue culture technique is difficult in monocotyledonous species particularly in Gramineae family (Sears and Deckard, 1982) compared to dicots. As a member of the family, wheat is also a recalcitrant crop that limits the utilization of tissue culture technique for crop improvement (Vasil and Vasil, 1986). If a suitable protocol for plant regeneration from mature embryogenic callus is available, wheat transformation may be enhanced throughout the year. Although mature embryos yield low callus, their availability throughout the year makes them an excellent ex-plant source.

Recently, a number of advances have been made in the development and optimiza- 
tion of procedures for transformation of several monocot crops including wheat (Altpeter et al., 1996; Blechl and Anderson, 1996; Barro et al., 1997; Cheng et al., 1997; Dobrzanska et al., 1997; Takumi and Shimada, 1997). For practical use in breeding programs, a large number of independently transformed lines are desirable so that those with stable transgene integration and a high level of expression can be selected (Altpeter et al., 1996). The number of transformed plant lines can be increased either by improving the efficiency of transformation or by reducing the time required for their production (Altpeter et al., 1996). Transformation of monocots, however, is still inefficient (Barro et al., 1997; Cheng et al., 1997; Dobrzanska et al., 1997; Takumi and Shimada, 1997). Most procedures, therefore, have focused on shortening the time frame for the production of transgenic plants (Altpeter et al., 1996; Blechl and Anderson, 1996). These procedures typically consist of inducing short-term morphogenic callus from the epidermal or subepidermal cell layer of the scutellum of immature embryos (Maes et al., 1996). After bombardment, the embryos are kept on callus induction medium with no selection or with low selection (e.g., 1.0-3.0 $\mathrm{mg} / \mathrm{L}$ bialophos) for a short period (2-4 weeks) for production of embryoids. After this stage, plant regeneration is usually induced on medium containing none or a minimal level of auxin or a mixture of cytokinins and auxins (Altpeter et al., 1996). These manipulations generally produce many regenerants but few true transformants. The transformation efficiencies are usually 0.1-2.5\% (Weeks et al., 1993; Nehra et al., 1994; Altpeter et al., 1996; Barro et al., 1997; Dobrzanska et al., 1997).

It is a general notion that monocotyledonous plants are more difficult explants for tissue culturing as compared to dicotyledonous because they lack the ability for secondary growth through cambium or cambium like tissues. In current days, the monocotyledonous are cultured and regenerated from different explant materials but plants that recovered are rather smaller and the competence for regeneration was lost within a short period of time. The objectives of current study were to investigate the variability present in Pakistani wheat varieties for callus induction capability and to monitor reducing sugar contents in the induced calli of selected varieties.

\section{MATERIAL AND METHODS}

\section{Plant material}

The plant material used in this study were 10 wheat varieties viz; Punjab-81, Punjab-96, Shahkar-95, Zarghoon-79, Rohtas-90, MH-97, Pasban-90, ZA-77, Sutlaj-86, Kohinoor-83. These varieties were developed by various research groups and institutions and have been in cultivation in the country over the past several decades. The material was selected based on plant height and drought tolerance parameters. Mostly it was from semi-dwarf varieties among which some were known to be drought tolerant while others were susceptible.

Seeds were treated using three sterilizing agents, i.e., absolute alcohol, mercuric chloride and bleach in five different manners to determine relative efficiency of sterilizing agent against contamination during culturing procedure. In the first treatment, seeds were washed with absolute alcohol for $5 \mathrm{~s}$ then with $0.1 \%$ mercuric chloride for $5 \mathrm{~s}$ and at last with $10 \%$ bleach for $10 \mathrm{~min}$. In the second treatment, mercuric chloride concentration was 
reduced to $0.05 \%$ by keeping the other factors constant. In the third treatment, the sterilization time with $10 \%$ bleach was reduced to $5 \mathrm{~min}$ by keeping other factors constant. In the fourth treatment, bleach sterilization time was reduced to 4 min. In the fifth treatment, the sterilization time of bleach was further reduced to $3 \mathrm{~min}$.

\section{Growth regulators, media preparation, and callus induction}

The growth regulators used in this study were kinetin and 2,4-D. These were prepared according to their dissolution principle in the solvent. Generally, kinetin is best soluble in $\mathrm{HCl}$, while 2,4-D in ethanol. Kinetin was prepared by dissolving $25 \mathrm{mg}$ kinetin powder in $2 \mathrm{~cm}^{3} 0.2 \mathrm{~N} \mathrm{HCl}$, warmed in water bath, slowly diluted to $100 \mathrm{~mL}$ with doubledistilled water and stored in refrigerator at $4^{\circ} \mathrm{C} .2,4-\mathrm{D}$ was prepared by dissolving $50 \mathrm{mg}$ powder 2,4-D in $3 \mathrm{~mL}$ ethanol in a warm water bath gradually diluted to $100 \mathrm{~mL}$ with double-distilled water and stored in refrigerator at $4^{\circ} \mathrm{C}$.

MS medium was used for callus induction that contains several micro- and macronutrients in addition to important vitamins (Murashige and Skoog, 1962). One-liter MS medium was prepared using nutrient solution and gelling material. The nutrient solution was first prepared according to the following procedure: $300 \mathrm{~mL}$ double-distilled water was poured in a beaker having a magnetic stirrer and placed on electric stirrer plate. While gently stirring, $100 \mathrm{~mL}$ macronutrients and iron stock solution was added. Then, $10 \mathrm{~mL}$ vitamins and micronutrients solution, $30 \mathrm{~g}$ sucrose, $1 \mathrm{~mL}$ kinetin, $4 \mathrm{~mL}$ 2,4-D, $2 \mathrm{~g}$ casein hydrolysate, and $0.1 \mathrm{~g}$ myo-inositol were added. The volume was made up to $990 \mathrm{~mL}$ in measuring cylinder with distilled water. $\mathrm{pH}$ was adjusted to 5.8-5.9 with $0.2 \mathrm{KOH}$ and volume was adjusted to $1000 \mathrm{~mL}$ with distilled water. Nutrient solution was then transferred to 1-liter flask and $8 \mathrm{~g}$ agent (gelling) was added. To dissolve the agar completely and uniformly it was heated for $15 \mathrm{~min}$. Later, the medium was poured into test tubes for callus culturing, the tubes were plugged and the medium was sterilized by autoclaving at $121^{\circ} \mathrm{C}$ for $20 \mathrm{~min}$.

Before shifting glass ware and tools to be used in culturing process, laminar flow unit was sprayed with $70 \%$ ethanol to avoid the contamination caused by the microorganism. The unit was then turned on and was allowed to run for 30 min before starting the work. Laminar flow is equipped with high-efficiency particulate air filter with a positive air pressure blowing outward from the rare of chamber in order to prevent contamination caused by microbes entering laminar flow unit from outside. After eliminating all sources of contamination, the seeds and all autoclaved tools were shifted to laminar flow unit.

A sample of 20-25 seeds was used to culture each variety. Seeds were dipped in absolute alcohol for $10 \mathrm{~s}$ and then rinsed five times with sterilized distilled water. After this treatment, the seeds were washed with $0.1 \%$ mercuric chloride in universal bottle in initial experiments just for $10 \mathrm{~s}$. After that seeds were washed with sterilized distilled water for five times. In later cases, mercuric chloride concentration was reduced to $0.05 \%$ to avoid blackening of seeds. Then, the seeds were washed with $10 \%$ bleach initially for $10 \mathrm{~min}$ and gradually reduced to $3 \mathrm{~min}$. At last the seeds were again washed with sterilized distilled water for five times. During each step of sterilization the universal bottle and bottles containing sterilizing agents were flamed. One seed was cultured per test tube having $10 \mathrm{~mL}$ MS media. Forceps were also flamed before use to prevent contamination. In addition to this, cotton plugs and test tube necks were also flamed before and after seed 
culturing. Each seed was picked with forcep and transferred to test tube and plugged. The whole process was carried out in the vicinity of 6 inches around the flame of spirit lamp. Cultured seeds were shifted to growth room. These cultures were kept in culture room at a 16-h light/8-h dark cycle and $23-24^{\circ} \mathrm{C}$.

A regular monitoring protocol was observed to obtain the induced callus from each variety. Induced calli in the test tubes were sub-cultured three times to increase the quantity of callus for reducing sugar analysis for each genotype.

\section{Extraction of reducing sugar from induced wheat callus}

About $0.05 \mathrm{~g}$ tissue was frozen in liquid nitrogen. This material was crushed in 4 $\mathrm{mL}$ methanol:chloroform:water $(12: 5: 1)$ and the product was centrifuged for 5 min and supernatant was removed. Re-extraction of the pellets in the same volume of extraction buffer was carried out.

\section{RESULTS AND DISCUSSION}

In the present study, ten wheat varieties were selected for callus induction response from semi-dwarf and drought tolerant germ plasm. Seeds of each variety were treated with three sterilizing agents to identify relative efficiency of the treatments in controlling contamination during callus induction. The first treatment of washing the seeds with absolute alcohol for 5 s caused $29 \%$ of seed mortality with no contamination and blackening.

The second treatment with $0.05 \%$ mercuric chloride resulted in $15 \%$ of seed mortality with blackening and no contamination. In the third treatment, where the sterilization time was reduced to $5 \mathrm{~min}$, the mortality rate was $5 \%$ with very light blackening and $2 \%$ contamination. The fourth treatment has shown $5 \%$ contamination, $2 \%$ mortality rate and light brownish seed discoloration. In the fifth and last treatment, the sterilization time of bleach was further reduced to $3 \mathrm{~min}$, which resulted in no mortality, 7\% contamination and no blackening of seeds. It can be concluded that surface sterilization of wheat seeds with a combination of absolute alcohol $(5 \mathrm{~s}), 0.05 \%$ mercuric chloride ( 5 s), and $10 \%$ bleach ( $3 \mathrm{~min}$ ) give excellent results with $0 \%$ mortality rate of seeds and no contamination.

\section{Callus induction}

The callus induction was found to be genotype-dependent. Although the same in vitro conditions were provided to all varieties, there was a marked difference between their callus induction capability, size, and type of callus (Figures 1-4). Maximum callus induction was found in Punjab-96 (86.36\%) followed by Punjab-81 (81.81\%) and Zarghoon-79 (72.72\%). Some other prominent genotypes that showed good callus induction were ZA-77 and MH-97 with $63.63 \%$ each one. Shahkar-95 showed $54.54 \%$, Sutlaj-86 showed $45.5 \%$ callus induction. Rohtas-90 and Pasban-90 showed similar callus induction of $40.9 \%$. Kohinoor- 83 showed least callus induction capability, which was of $36.34 \%$ (Figure 1). 


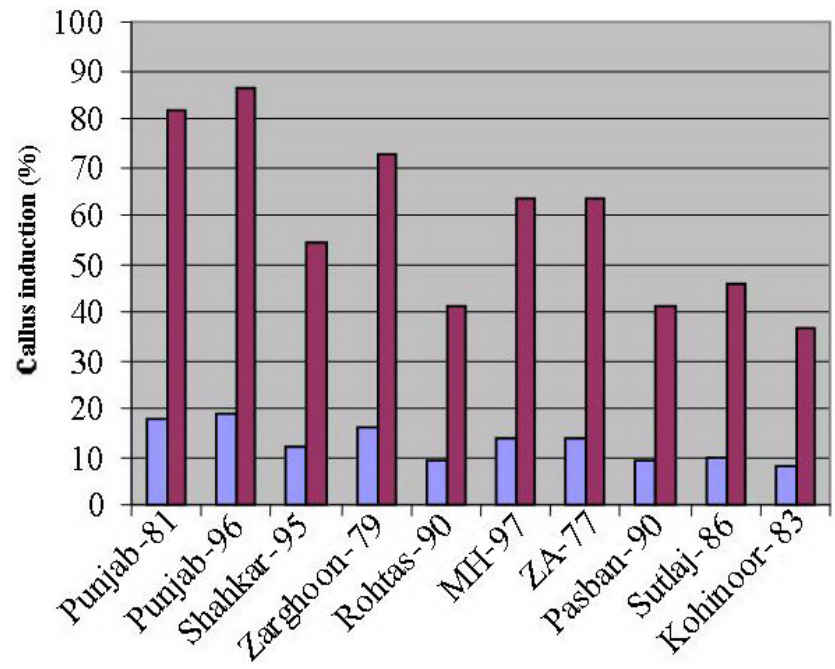

$\square$ Callus induction in the 1st week

$\square$ Callus induction in the 4th week

Figure 1. Callus induction of cultivated wheat varieties.

Two types of calli were induced in the wheat cultured cultivars. One was compact, hard and yellowish-green and the other was soft and watery (Figure 2). The texture of the calli of Punjab-96, Punjab-81, MH-97, ZA-77, Rohtas-90, Sutlaj-86, and Shahkar-95 was compact, hard and embryogenic, while Kohinoor-83, Pasban-90 and Zarghoon-79 were found to be soft, delicate, watery, and non-embryogenic.

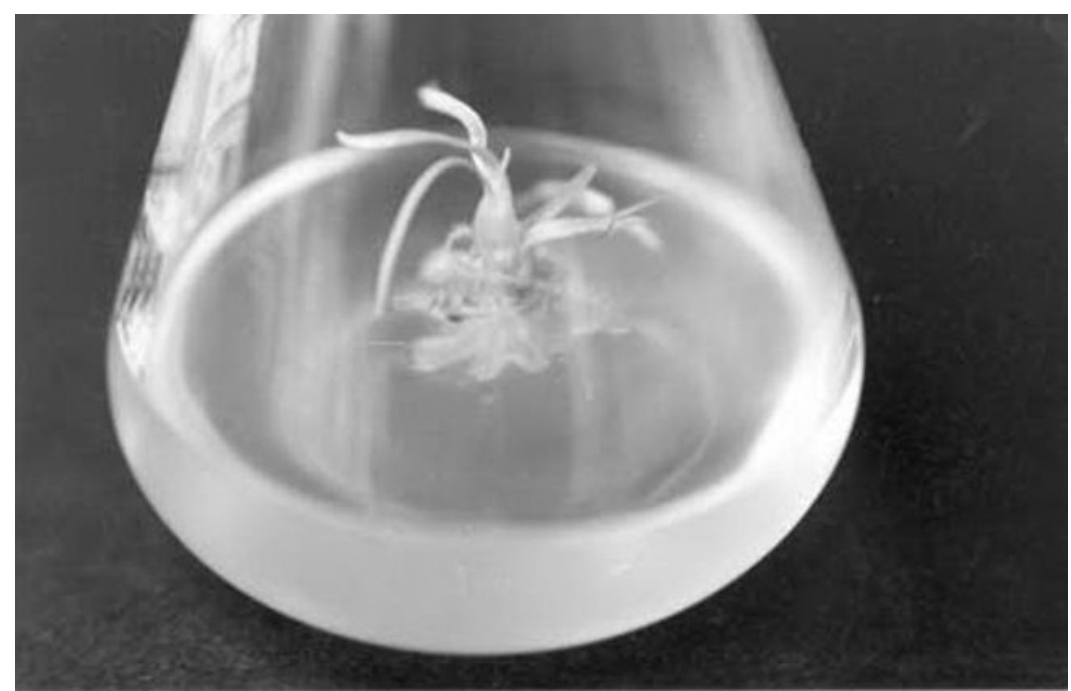

Figure 2. Callus induced on MS media from wheat seed. 
Sub-culturing of both types of callus from all genotypes that induced calli was successful (Figure 3). Each sub-culture further induced the calli and eventually showed green shoots or plantlets (Figure 4).

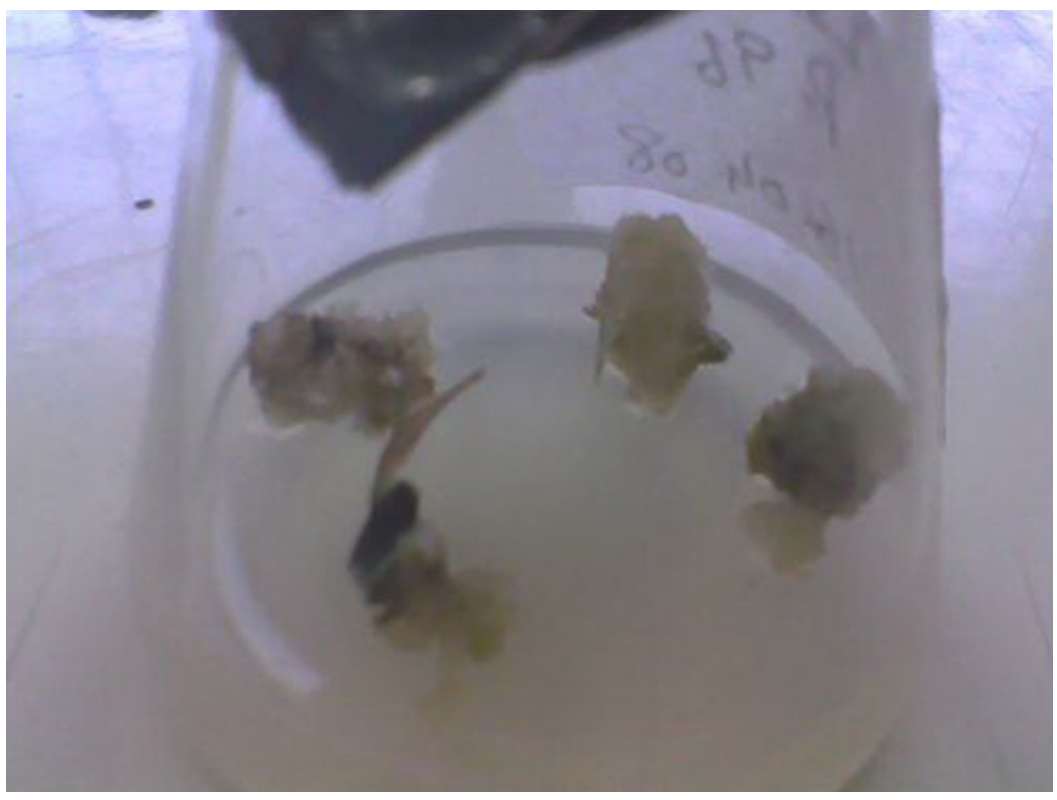

Figure 3. Sub-cultured calli of wheat variety Punjab-96.

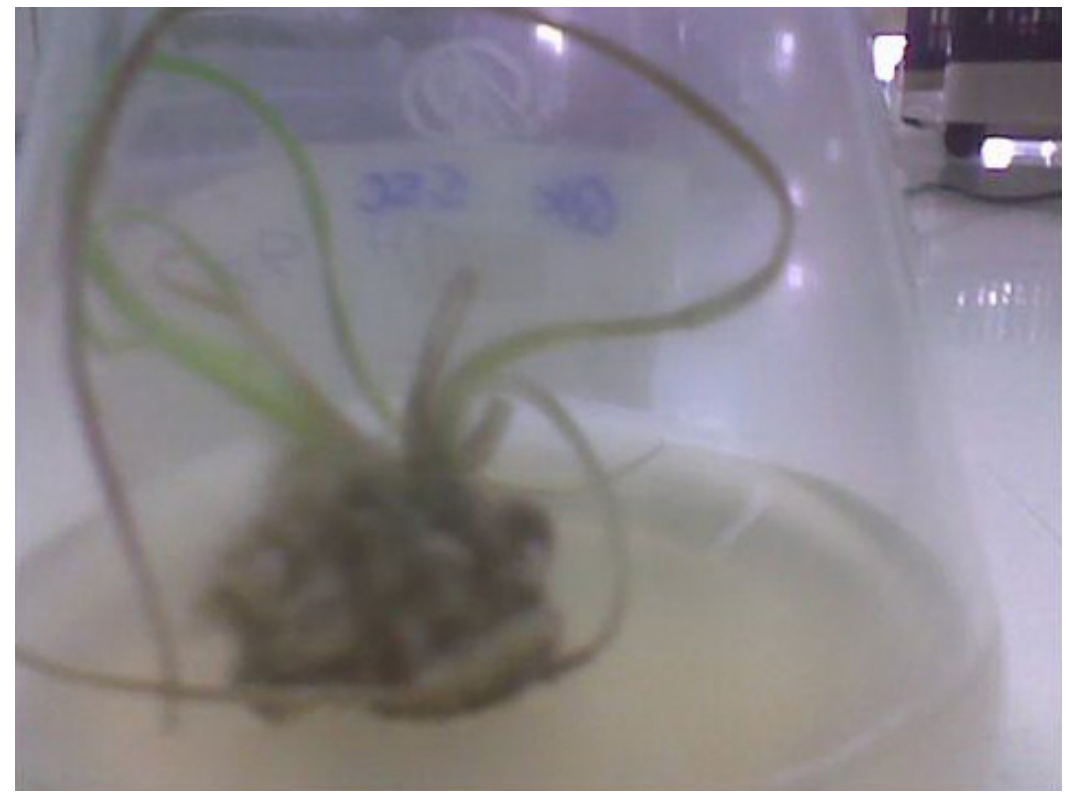

Figure 4. Shooting and rooting from a sub-cultured callus of wheat variety Punjab-96. 
Inoculated seeds not only induced callus but also showed germination with different frequencies depending upon the genotype. Punjab-96, Shahkar-95, Rohtas-90, MH-97, ZA-77, and Sutlaj-86 showed maximum germination of shoots and roots having $85.71,82.60,87.5,83.33,81.8$, and $81.8 \%$ germination, respectively, while Punjab-81 and Pasban-90 showed comparable germination of $60 \%$ and Zarghoon-79 and Kohinoor-83 showed $63.63 \%$ germination (Figure 5).

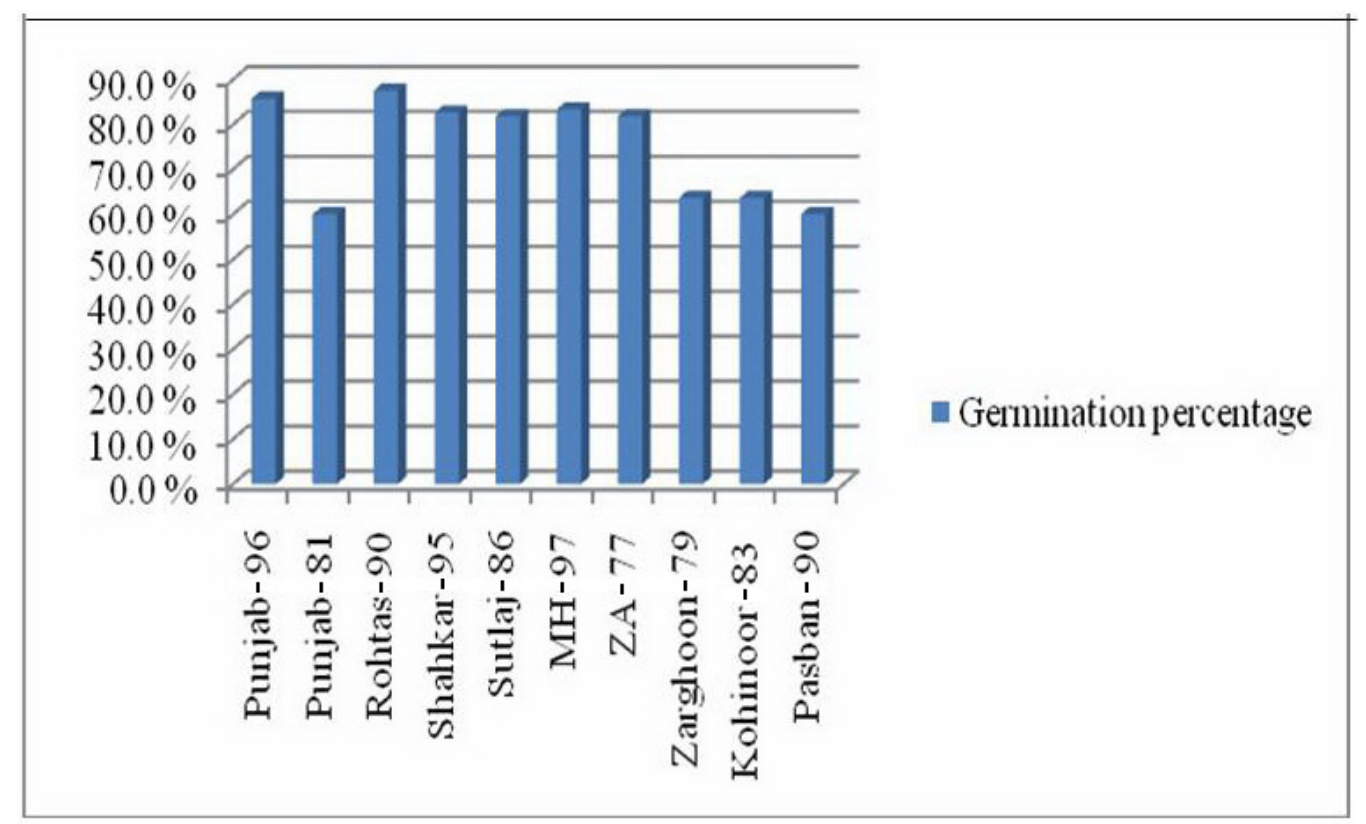

Figure 5. Percent germination from seeds of different wheat varieties.

Variation in the average shoot length was found to be genotype-dependent. Highest shoot length was observed in Punjab-81 and Punjab-96, i.e., 4.7 and 4.8 inches, and Rohtas-90, Shahkar-95 and Sutlaj-86 showed average shoot lengths of 4.4, 4.1, and 3.9 inches, respectively. MH-97, ZA-77, and Zarghoon-79 showed average shoot length of 3.7, 3.4, 3.33 inches, respectively, while Kohinoor- 83 and Pasban- 90 showed the least average shoot length of 2.9 and 2.4 inches (Figure 6).

Not significant but a variable trend was found in terms of reducing sugar content in the wheat germ plasm (Figure 7). The amount of reducing sugar in the induced calli was found to be highest in the variety Sutlaj-86 that can be due to its resistance mechanism for stress tolerance. The cultivars Punjab-81, Punjab-96, Shahkar-95, MH-97, and Kohinoor-83 showed almost similar sugar concentration but less than Sutlaj-86. This declining trend was found in Pasban-90 and ZA-77 followed by Rohtas-90, which showed the least reducing sugar concentration (Figure 7). A reducing sugar content represents the stress resistance in the plant. The wheat containing higher amount of reducing sugar will be more resistant but this resistance will be at the expense of their growth. Plant will show short stature and narrower leaf width. 


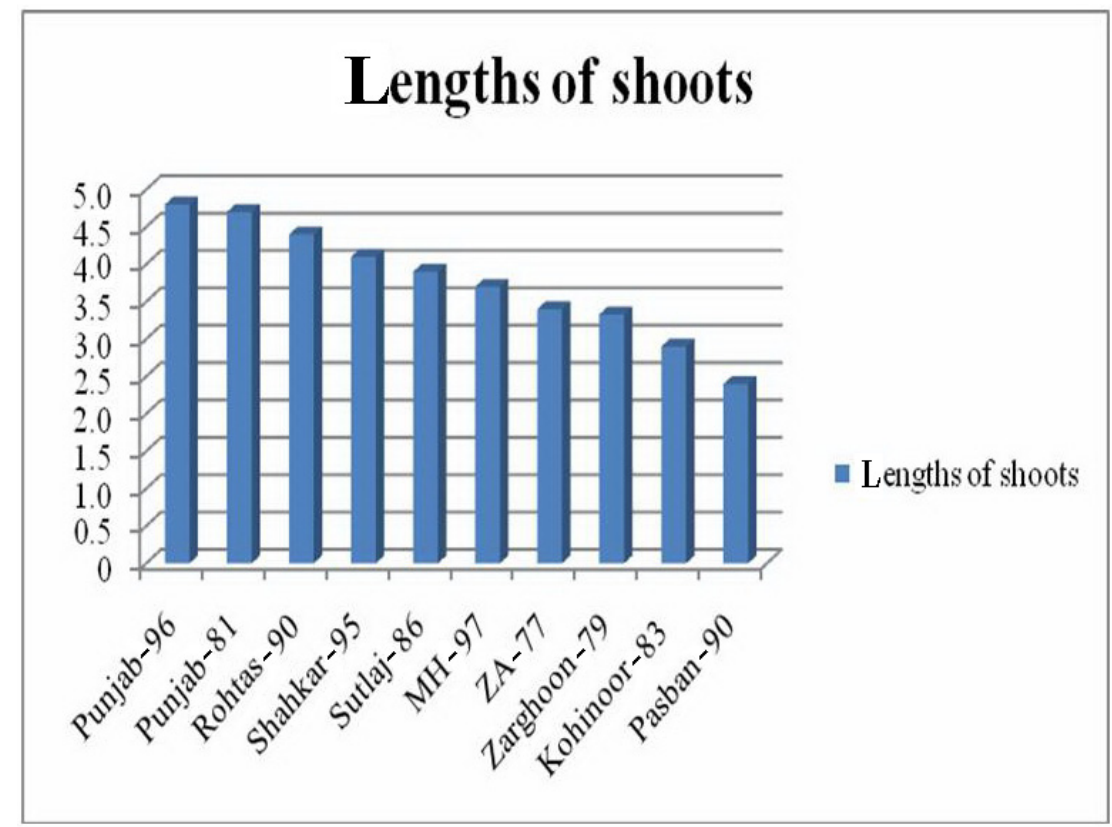

Figure 6. Shoot lengths of different cultivated wheat varieties.

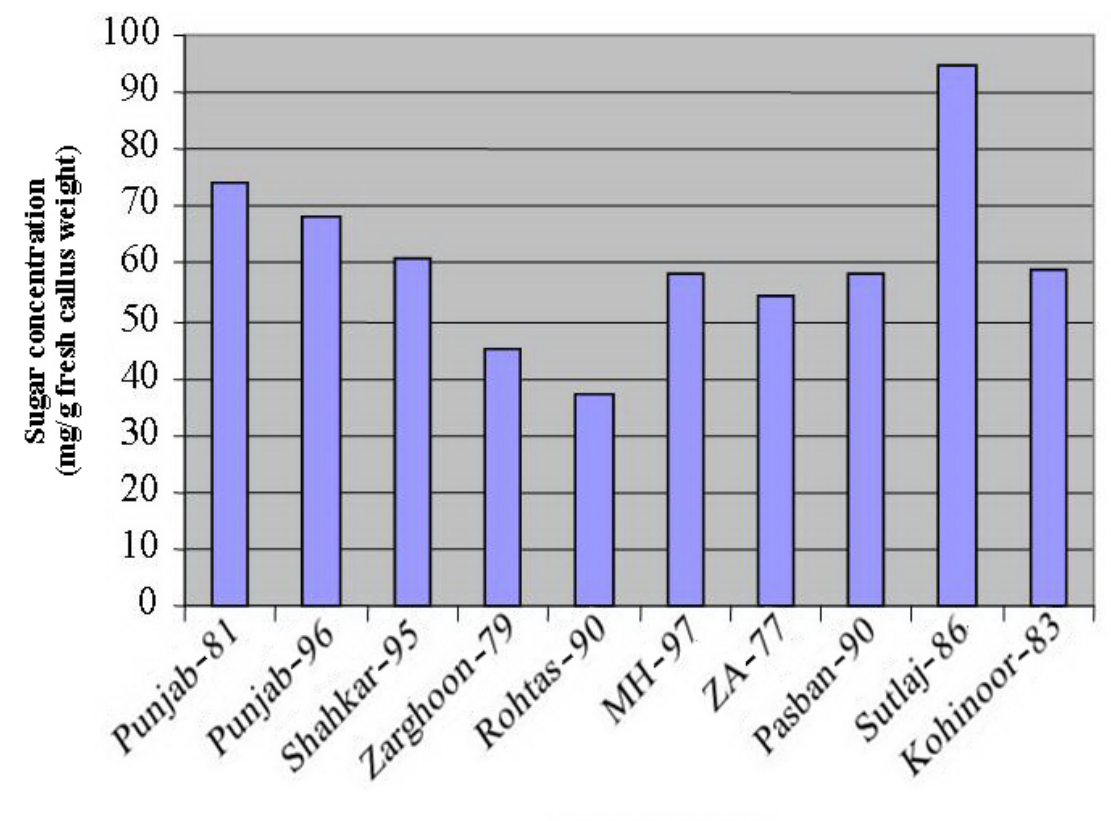

\section{Wheat varieties}

Figure 7. Total reducing sugar concentration in induced calli. 
The yield and quality of cereal grains have been gradually but substantially improved during the past few decades by breeding and selection, but realistically such changes cannot be sustained indefinitely. More importantly, plant improvement by traditional breeding methods is severely hampered by the rather limited gene pool owing to sexual incompatibility, even between closely related species, and to the time scale of most breeding programs. With the doubling of the world population expected within the next 40-50 years, there is an urgent need to increase food production rapidly to meet the needs of expanding humanity. Much attention is shifted towards crop improvement through biotechnological means as an efficient aid to traditional crop improvement programs. One of such biotechnological techniques is the plant tissue culture. Tissue culture techniques are becoming increasingly popular as an alternative means of plant vegetative propagation, mass production of chemicals, and genetic engineering. The primary goal of plant tissue culture is crop management. This involves asexual methods of propagation to generate whole plant from single cells (Chawla, 2000). In order for successful selection and genetic manipulation to occur, one must have successful in vitro plant regeneration. Clonal propagation allows many thousands of genetically identical plants to be derived from a single cell or tissue in a relatively short amount of time.

Heritable variation is often observed in plants regenerated from tissue, cells and organ culture. Wheat has been the principal subject for investigating this phenomenon and several researchers have reported that different types of somaclonal variants are produced (Cheng et al., 1997). A body of evidence have been accumulated to show that induced variation includes agronomically useful traits. Such variation is significant in relation to the potential role of tissue culture in genetic manipulation and plant breeding programm. Although tissue culture studies for wheat improvement in Pakistan have been reported (Ullah et al., 2001), no study was initiated on the varieties grown in Northern areas of Pakistan. Therefore, a new, endosperm-supported callus induction method was developed using mesocotyls of mature wheat embryos. After seed germination under aseptic condition, most of the germ tissues were cut off and only a few millimeters of the mesocotyl tissue with the scutellum were used for callus induction. The seeds were placed with the furrow downwards in 2,4-D solution (6-8 $\mathrm{mg} / \mathrm{L}$ ). Proliferating callus tissues were already observed on the cut surface of the mesocotyls on the 2nd day after inoculation. In the MS nutrient medium, callus formation from the isolated scutella with attached mesocotyls was negligible even after 6 days. For shoot and root regeneration, the calli produced up to 10 days were removed from the seeds and transferred to a hormone-free MS medium. As shown by histological methods, the plantlets regenerated via organogenesis (Bartók and Sági, 1990).

The results of the current study showed that the best varieties among the selected ones for the callus induction were Punjab-96, Punjab-81, and Zarghoon-79. These varieties showed maximum callus induction capability and the variation between the induced callus qualities also gave best results for the Punjab-81 and Punjab-96. Therefore, their embryogenic induced callus can be used for wheat transformation and genetic engineering research. The highest reducing sugar concentration was found in the variety Sutlaj-86, which may further be checked for its stress resistance so that its gene pool can be utilized for the future genetic engineering research. In case it comes up as a potential candidate for stress resistance, the gene(s) responsible will be searched out using bioinformatics tools. Further it can be combined with the gene responsible for best callus induction quality so that the aim of best varieties production and their utilization for human welfare can be achieved. 


\section{REFERENCES}

Altpeter F, Vasil V, Srivastava V, Stoger E, et al. (1996). Accelerated production of transgenic wheat (Triticum aestivum L.) plants. Plant Cell Rep.16: 12-16.

Arzani A and Mirodjagh SS (1999). Response of durum wheat cultivars to immature embryo culture, callus induction and in vitro salt stress. Plant Cell Tissue Organ Cult. 58: 67-72.

Barro F, Rooke L, Bekes F, Gras P, et al. (1997). Transformation of wheat with high molecular weight subunit genes results in improved functional properties. Nat. Biotechnol. 15: 1295-1299.

Bartók T and Sági F (1990). A new, endosperm-supported callus induction method for wheat (Triticum aestivum L.). Plant Cell Tissue Organ Cult. 22: 37-41.

Blechl AE and Anderson OD (1996). Expression of a novel high-molecular-weight glutenin subunit gene in transgenic wheat. Nat. Biotechnol. 14: 875-879.

Chawla HS (2000). Introduction to Plant Biotechnology. Science Publishers Inc., Enfield.

Cheng M, Fry JE, Pang S, Zhou H, et al. (1997). Genetic transformation of wheat mediated by Agrobacterium tumefaciens. Plant Physiol. 115: 971-980.

Dobrzanska M, Krysiak C and Kraszewska E (1997). Transient and stable transformation of wheat with DNA preparations delivered by a biolistic method. Acta Physiol. Plant. 19: 277-284.

Duncan DR, Williams ME, Zehr BE and Widholm JM (1985). The production of callus capable of plant regeneration from immature embryos of numerous Zea mays genotypes. Planta 165: 322-332.

Gill KS and Gill BS (1994). Mapping in the realm of polyploidy: the wheat model. BioEssays 16: 841-846.

Green CE (1977). Prospects for crop improvement in the field of cell culture. HortScience 12: 131-134.

La Rue CD (1949). Culture of the endosperm of maize. Am. J. Bot. 34: 585-586.

Lührs R and Lörz H (1988). Initiation of morphogenic cell-suspension and protoplast cultures of barley (Hordeum vulgare L.). Planta 175: 71-81.

Maes OC, Chibbar RN, Caswell K, Leung N, et al. (1996). Somatic embryogenesis from isolated scutella of wheat: effects of physical, physiological and genetic factors. Plant Sci. 121: 75-84.

Murashige T and Skoog F (1962). A revised medium for rapid growth and biossays with tobacco tissue cultures. Physiol. Plant. 15: 473-497.

Nehra NS, Chibbar RN, Leung N, Caswell K, et al. (1994). Self-fertile transgenic wheat plants regenerated from isolated scutellar tissues following microprojectile bombardment with two distinct gene constructs. Plant J. 5: 285-297.

Ozagen M, Turet M, Altiinok S and Sancak C (1998). Efficient callus induction and plant regeneration from mature embryo culture of winter wheat (Triticum aestivum L.) genotypes. Plant Cell Rep. 18: 331-335.

Redway FA, Vasil V, Lu D and Vasil IK (1990). Identification of callus types for long-term maintenance and regeneration from commercial cultivars of wheat (Triticum aestivum L.). Theor. Appl. Genet. 79: 609-617.

Sarker RH and Biswas A (2002). In vitro plantlet regeneration and Agrobacterium-mediated genetic transformation of wheat (Triticum aestivum L.). Plant Tissue Cult. 12: 155-165.

Sears RG and Deckard EL (1982). Tissue culture variability in wheat: callus induction and plant regeneration. Crop Sci. 22: 546-550.

Takumi S and Shimada T (1997). Variation in transformation frequencies among six common wheat cultivars through particle bombardment of scutellar tissues. Genes Genet. Syst. 72: 63-69.

Ullah H, Chen JG, Young JC, Im KH, et al. (2001). Modulation of cell proliferation by heterotrimeric G protein in Arabidopsis. Science 292: 2066-2069.

Vasil IK (1987). Developing cell and tissue culture systems for the improvement of cereal and grass crops. J. Plant Physiol. 128: 193-218.

Vasil IK and Vasil V (1986). Regeneration in Cereal and Other Grass Species. In: Cell Culture and Somatic Cell Genetics of Plants. Volume 3. Plant Regeneration and Genetic Variability (Vasil IK, ed.). Academic Press, Orlando, 121-150.

Vasil V, Redway F and Vasil IK (1990). Regeneration of plants from embryogenic suspension culture protoplasts of wheat (Triticum aestivum L.). Bio/Technology 8: 429-434.

Weeks JT, Anderson OD and Blechl AE (1993). Rapid production of multiple independent lines of fertile transgenic wheat (Triticum aestivum). Plant Physiol. 102: 1077-1084.

Yamada Y, Yang ZQ and Tang DT (1986). Plant regeneration from protoplast-derived callus of rice (Oryza sativa L.). Plant Cell Rep. 5: 85-88. 